\title{
EPIDEMIOLOGIA DA DOENÇA RENAL POLICÍSTICA EM PACIENTES RENAIS CRÔNICOS NO MUNICÍPIO DE
} CAMPINAS ${ }^{1}$

Zélia Z. Lourenço de Camargo Bittencourt ${ }^{2}$

\section{RESUMO}

A carência de dados epidemiológicos da Insuficiência Renal Crônica Terminal (IRCT) no município de Campinas levou a realização deste estudo descritivo, que tomou como recorte a Doença Renal Policística, doença hereditária, passível de interferências preventivas através de detecção precoce e aconselhamento genético. O objetivo deste estudo foi conhecer a prevalência da IRCT e identificar os prováveis diagnósticos da população em tratamento dialítico no município de Campinas. A prevalência da Doença Renal Policística na população em tratamento dialítico permitiu identificar os indivíduos portadores, avaliar suas características epidemiológicas e demográficas e detectar o grau de conhecimento sobre o modo de transmissão da doença. Os resultados sugerem que o baixo nível social e de escolaridade dos pacientes dificultam o acesso à informação e orientação sobre a doença, apontando para a necessidade de ações preventivas de maior impacto na comunidade, utilizando um arsenal de tecnologias leves, com alternativas pedagógicas para os pacientes de baixa escolaridade, para que estes se apropriem de conhecimentos que os tornem mais autônomos.

PALAVRAS-CHAVE: Insuficiência renal crônica, Doença renal policística, Saúde Pública, Aconselhamento genético, Ações preventivas

\footnotetext{
${ }^{1}$ Este texto sintetiza alguns elementos da pesquisa da Dissertação de Mestrado em Saúde Coletiva, defendida em 1998 na Faculdade de Ciências Médicas UNICAMP: "Epidemiologia da Doença Renal Policística em familiares de pacientes com Insuficiência Renal Crônica em tratamento dialítico no Município de Campinas", tendo como orientadores Prof Dr Nelson Rodrigues dos Santos (Med Preventiva /FCM) e Prof Dr Gentil Alves Filho (Nefrologia / FCM/UNICAMP).

${ }^{2}$ Assistente Social - FCM/UNICAMP, Doutoranda em Saúde Coletiva FCM/UNICAMP.
} 


\section{INTRODUÇÃO}

Nos últimos anos, os países industrializados, observaram profunda transformação em seu perfil epidemiológico, caracterizada pela gradual e progressiva queda das doenças infecciosas e parasitárias e pela ascensão das doenças crônicas degenerativas. Os países em desenvolvimento também sofreram nas últimas décadas transformação semelhante (ARAÚJO, 1992).

A progressiva melhora nos níveis de saúde dos países desenvolvidos acentuou-se a partir das transformações sociais provocadas pela revolução industrial e urbanização, resultantes de mudanças significativas na disponibilidade de alimentos, nas condições de moradia, em medidas de saneamento básico, na distribuição de renda e na efetividade dos programas sociais.

As mudanças nos padrões de morbidade e mortalidade desses países correspondem a uma fase mais recente de um processo histórico secular, ao qual Omram apud Veras (1995, p. 320-337), denominou “transição epidemiológica”.

No Brasil, devido a suas dimensões continentais, geograficamente heterogêneas, onde o crescimento demográfico e a organização social têm características particulares, as transformações no perfil epidemiológico e demográfico tornaram-se evidentes nas últimas décadas.

Laurenti (1990) sinaliza que, atualmente, nosso país encontra-se em estágio intermediário da transição: apresenta um perfil epidemiológico polarizado, com aumento da morbimortalidade por doenças crônico-degenerativas, de destacado custo social, e com a permanência ou até mesmo com o recrudescimento de parte das moléstias infecciosas e parasitárias, ao contrário do que acontece com os países industrializados, onde as doenças crônicas só passaram a assumir papel preponderante após o virtual controle das enfermidades transmissíveis. 
Observa-se também no Brasil que as disparidades geográficas e econômicosociais explicam a existência de regiões com padrões de saúde comparáveis aos de países desenvolvidos, simultaneamente com regiões cujos índices de mortalidade são semelhantes aos dos países mais pobres do hemisfério sul.

Araújo (1992) refere que a polarização social apresentada pelos desníveis entre grupos populacionais, dentro de uma mesma região, estado ou cidade, constitui a expressão das desigualdades de renda, da carência, de alimentação, moradia, saneamento, educação e também a dificuldade de acesso aos serviços de saúde.

Devido ao processo de urbanização, os centros urbanos configuram um locus específico de reprodução da realidade macrossocial do país (REICHENHEIM; WERNECK, 1994). Cerca de 75\% da população brasileira vivem em área urbana, com tendência crescente, estimando-se aproximar de $85 \%$ na primeira década do recente século.

A urbanização implica, portanto, em consideráveis mudanças no cotidiano (NETTO; FALCÃO, 1989) e no modo de vida, de produção e reprodução social da população, nos seus hábitos alimentares, e numa série de fatores ambientais a que está exposta no processo saúde-doença.

Paradoxalmente, superadas as moléstias da pobreza e de fome, as sociedades ditas desenvolvidas estão agora expostas às doenças degenerativas, conseqüência natural do processo de envelhecimento, de etiologia muitas vezes ainda não completamente esclarecida.

Nos últimos anos verificamos uma variedade de doenças e síndromes crônico degenerativas, de origens multifatoriais, que, surgindo insidiosamente, provocam efeitos deletérios na saúde da população. Em decorrência de sua importância, têm constituído foco de interesse epidemiológico, sendo tratadas no enfoque da Saúde Pública, que 
preconiza ações de promoção, proteção e recuperação da saúde em diferentes grupos humanos, expostos a riscos específicos.

Nesse grupo de doenças e síndromes incluímos a Insuficiência Renal Crônica que, à medida que evolui para o estágio terminal, aparece como uma das enfermidades crônicas das mais debilitantes e onerosas.

O tema do presente trabalho é o estudo de parâmetros epidemiológicos da Insuficiência Renal Crônica no Município de Campinas, tomando-se como recorte a Doença Renal Policística.

\section{INSUFICIÊNCIA RENAL CRÔNICA TERMINAL}

Insuficiência Renal Crônica Terminal (IRCT) é a fase final de uma série de doenças que comprometem os rins irreversivelmente. É, portanto, uma síndrome provocada por várias doenças, que vão progressivamente reduzindo a função renal e, segundo Marcondes (1976), podem ser agrupadas em:

Doenças renais, sendo mais freqüentes as glomerulonefrites de evolução crônica, tuberculose renal e os processos inflamatórios tubulointersticiais.

Doenças do trato urinário, como as pielonefrites e calculoses, alterações do colo vesical, aumento prostático, estreitamentos uretrais e outros.

Doenças sistêmicas, como a hipertensão arterial nas formas maligna e benigna; doenças difusas do tecido conectivo (lúpus); problemas metabólicos (diabetes mellitus, gota, deficiência de potássio, hipercalcemia, mieloma múltiplo), coagulopatias de consumo: intoxicações crônicas com certos metais como o chumbo, entre outras.

Doenças de origem hereditária, como o rim policístico e síndrome de Alport.

Dados do V Registro Brasileiro de Diálise e Transplante Renal (1994) apresentam como causas mais freqüentes de Insuficiência Renal Crônica Terminal em 
nosso meio as Glomerulopatias (26\%), a Hipertensão Arterial (22\%), Diabetes Mellitus (17\%), Diagnóstico Indeterminado (12\%), Outras Causas (11\%), Pielonefrites (5\%), Rim Policístico (4\%) e Lúpus (2\%).

Destacam-se em termos epidemiológicos, pela sua alta incidência em nosso meio, as Glomerulopatias, a Hipertensão Arterial e o Diabetes Mellitus, responsáveis por $65,0 \%$ das causas de falência renal, enfatizando a necessidade de implantação de programas de prevenção, diagnóstico e tratamento destas doenças, com o intuito de retardar o agravamento e ampliar o tempo de vida saudável da população.

A IRCT acomete predominantemente indivíduos do sexo masculino, atingindo todas as faixas etárias e classes sociais, sendo sua maior incidência na população entre 20 e 50 anos, período em que se encontra em plena fase produtiva.

Pacientes com tais doenças necessitam de tratamento substitutivo da função renal, sendo os procedimentos dialíticos as modalidades mais utilizadas, como a hemodiálise (HD), a diálise peritonial intermitente (DPI) e a diálise peritonial ambulatorial contínua (DPAC), além do transplante renal (TX). Todos esses tratamentos são de alta complexidade, e alto custo, demandando profissionais qualificados e atualizados quanto aos avanços tecnológicos na área.

Desde 1975, em nosso país, o Governo Federal custeia o tratamento de cerca de 95\% dos pacientes renais crônicos, segundo critérios e normas estabelecidas para o credenciamento e funcionamento das unidades de diálise e transplante renal, apesar dos limitados recursos econômicos destinados à área de saúde (AJZEN; SESSO, 1995).

Há poucas publicações na literatura nacional sobre dados epidemiológicos e demográficos do tratamento dialítico no Brasil, e somente em anos recentes observa-se preocupação com a sistematização de registros em nosso meio. 
Ajzen e Sesso (1995) estimam que haja cerca de 23.000 pacientes com IRCT em tratamento dialítico distribuídos pelo território nacional, cifra considerada subestimada quando comparada com a prevalência em várias partes do mundo. Afirmam também que há indícios de que mais de $25 \%$ dos pacientes com IRCT, que necessitariam de tratamento dialítico em São Paulo, não têm acesso a programas de diálise por motivo relacionado principalmente ao fato de não ter sido a doença diagnosticada em tempo oportuno.

A relativa prevalência de várias doenças renais primárias entre os pacientes também difere entre os vários países (TAB. 1).

TABELA 1

Principais doenças primárias - Registros internacionais

\begin{tabular}{llccc}
\hline País & GNC & DM & HAS & R POLIC \\
\hline E.U.A. & $21 \%$ & $30 \%$ & $28 \%$ & $6 \%$ \\
\hline JAPÃO & $42 \%$ & $28 \%$ & $6 \%$ & $3 \%$ \\
\hline EDTA & $23 \%$ & $5 \%$ & $12 \%$ & $8 \%$ \\
\hline ITALIA & $35 \%$ & $12 \%$ & $27 \%$ & $9 \%$ \\
\hline CANADÁ & $19 \%$ & $25 \%$ & $11 \%$ & $8 \%$ \\
\hline AUSTRÁLIA & $38 \%$ & $14 \%$ & $9 \%$ & $4 \%$ \\
\hline AM LATINA & $23 \%$ & $17 \%$ & $21 \%$ & $4 \%$ \\
\hline BRASIL & $26 \%$ & $17 \%$ & $22 \%$ & \\
\hline
\end{tabular}

Dados da literatura apontam o Diabetes é a causa prevalente nos E.U.A. e Canadá, enquanto a Glomerulonefrite aparece como a principal causa no Japão, na Europa, na Austrália, e América Latina. Em todos esses países a Hipertensão Arterial, como doença primária, tem aumentado nos últimos anos, como também tem aumentado o número de idosos nos programas de substituição renal. 
Agodoa e Eggers (1995) afirmam que as mais importantes doenças primárias desencadeadoras de IRCT nos Estados Unidos incluem o Diabetes Mellitus, a Hipertensão, as Glomerulonefrites e as Doenças Císticas Renais.

\section{DOENÇA RENAL POLICÍSTICA AUTOSSÔMICA DOMINANTE}

Entre as principais causas de IRCT encontramos as nefropatias hereditárias, sendo a Doença Renal Policística a mais significativa.

Segundo Broyer e Gagnadoux (1992) a expressão “doença renal policística” está reservada para duas doenças císticas hereditárias: doença renal policística autossômica recessiva e doença renal policística autossômica dominante.

A doença renal policística autossômica dominante forma adulta, é definida geneticamente pela dominância hereditária e é observada pelas dilatações císticas de todas as partes do néfron (BROYER; GAGNADOUX, 1992).

Teoricamente a doença está presente desde o início da vida fetal, mas na maioria dos casos manifesta-se clinicamente na fase adulta, quando a função renal diminui até alcançar o estágio terminal (FRANZ; REUBI, 1983).

O diagnóstico da doença renal policistica no adulto é mais fácil, principalmente quando associado à história familiar positiva. Estima-se que apenas 50\% dos pacientes são diagnosticados clinicamente durante suas vidas (PIRSON; GRUNFELD, 1992).

Na grande maioria dos casos a doença é assintomática e diagnosticada em exame clínico de rotina ou durante investigação genética (PIRSON; GRUNFELD, 1992), geralmente entre a terceira e quarta décadas da vida (SEDMAN, 1987).

Hipertensão arterial (HA) é um aspecto clínico importante, manifestando-se entre 13 a 20\% dos pacientes com doença policística e aumentando com o declínio da função renal A progressiva perda da função renal é a mais freqüente complicação dos 
portadores da doença. Estudos mostram que quando isso ocorre, o estágio final da perda dá-se em média ao redor dos 50 anos, sendo que em 76\% dos casos a diálise regular foi iniciada entre os 40 e 59 anos de idade (SIMON apud PIRSON; GRUNFELD, 1992)

Diagnósticos pré-sintomáticos são realizados com o objetivo de detectar, nas famílias, as pessoas em risco, para providências quanto à orientação, aconselhamento genético e seguimento clínico. O diagnóstico, entretanto, pode ter impacto psicológico negativo, especialmente se a informação médica não for claramente comunicada (PIRSON; GRUNFELD, 1992).

Os autores supracitados ainda enfatizam que a investigação em familiares suscetíveis é recomendada a indivíduos expostos ao risco, maiores de 18 anos, que procuram o exame e tenham apropriado entendimento do potencial de riscos e benefícios, uma vez que a orientação e a informação visam basicamente beneficiar a pessoa e a prole.

Watson (1997) enfatiza a validade do aconselhamento genético, quando o diagnóstico for confiável, para pacientes em idade reprodutiva, uma vez que o diagnóstico precoce permite detectar e tratar a hipertensão e as infeccões urinárias. Protagonistas desta posição também encorajam o diagnóstico o mais precocemente possível.

\section{INFORMAÇÃO, ORIENTAÇÃO E ACONSELHAMENTO GENÉTICO}

Sendo a doença renal policística geneticamente determinada e acarretando repercussões na reprodução humana, a adequada informação genética e clínica deve ser dada a famílias afetadas, pois o diagnóstico pode influenciar o planejamento familiar e intervenção clínica. 
A informação constitui um eixo central para o direito e exercício da cidadania e para subsidiar a tomada de decisões dos indivíduos (FALEIROS, 1996).

O aconselhamento genético é um procedimento componente da conduta médica, tão importante quanto às providências terapêuticas. Sua omissão pode ser considerada falha médica grave, passível de processo penal.

Ramalho, Bertuzzo e Silva (1994) referem que o aconselhamento traduz uma situação em que os clientes anseiam por uma informação genética, para esclarecer um problema ou dúvida nessa área, e em geral procuram espontaneamente a orientação da equipe multiprofissional. Seria, portanto, um aconselhamento sobre um risco genético.

Já a orientação genética seria o processo de conscientização de portadores de anomalias hereditárias, envolvendo aspectos educacionais e reprodutivos, oferecidos na ausência de solicitação por parte dos clientes. A relação equipe multiprofissionalfamília pode evoluir de orientação para aconselhamento e vice-versa, sempre exigindo dos profissionais sensibilidade e preparo.

O aconselhamento genético é parte do processo assistencial e, ao contrário de outros procedimentos médicos, tem caráter não-diretivo e não coercitivo.

Ramalho (1986) tem incentivado a implantação no Brasil de programas opcionais e bem controlados de genética e saúde pública, principalmente os referentes a algumas doenças hereditárias. Refere ainda que estudos de avaliação desses programas demonstram que as orientações genéticas fornecidas pelos mesmos têm produzido bons resultados, tanto em termos cognitivos (assimilação das informações fornecidas), pragmáticos (utilização dessas informações) quanto psicossociais.

A prevenção assume, portanto, grande centralidade no contexto onde se.Pretende a participação da população em risco, cabendo ao Estado promovê-la, nos serviços públicos e privados, seja através de serviços diretos ou de ações mais globais. A 
prevenção envolve trabalho profissional, recursos, intervenções e precisa superar a significação de apenas 'prevenir a cronicidade’ como única possibilidade de ação em nível primário. Abrem-se horizontes para a prevenção secundária e terciária, implicando mudanças institucionais, culturais e ideológicas, refletindo na alteração de comportamento dos atores sociais envolvidos (FALEIROS, 1996).

Ainda Faleiros (1996) enfatiza que a complexidade das questões no âmbito das políticas sociais (saúde e outras) implicam não só uma interação de poderes e atores diversificados mas de saberes, exigindo um enfoque multidisciplinar na intervenção. $\mathrm{O}$ poder e o saber de cada profissional passam a 'ser mais relativizado' exigindo novas especializações, dando-lhe maior autonomia e competência para compreender os problemas complexos e fundamentar a intervenção.

Cabe também ressaltar a contribuição de Merhy (1997) sobre o cotidiano do trabalho em saúde e do processo de gestão, quando se pretende criar intervenções de impacto no interior de cada serviço, “construindo um outro proceder em saúde que se oriente pela construção de um vínculo efetivo entre o usuário e os trabalhadores do setor, na busca de uma resolutividade e em ganhos de autonomia dos usuários perante seus modos de andar na vida”. Para isto é necessário :

“- Garantir o acesso dos usuários às ações de saúde, ofertando múltiplas opções de conhecimento e tecnológicas para enfrentar os distintos problemas de saúde,

- Acolher os usuários em todos os momentos de relacionamento com os mesmos,

- Dar a máxima resolutividade às ações de saúde, procurando impactar os quadros de morbi-mortalidade, a partir da associação de todas as ações de saúde individuais e coletivas, tecnologicamente disponíveis”. 
Ainda de acordo com Merhy (1997), o processo de trabalho sob a óptica do trabalho vivo, criativo, em torno das “tecnologias leves”3 , tecnologia de e das relações, pode gerar alterações significativas no modo de agir em saúde, expressas em dimensões assistenciais do trabalho como: a relação de acolhimento, a criação de vínculo, a produção da resolutividade e a criação de maiores graus de autonomia do usuário.

\section{OBJETIVOS E METODOLOGIA}

Tendo em vista a inexistência de dados epidemiológicos da IRCT no município de Campinas, e considerando que a doença renal policística é a patologia hereditária autossômica dominante passível de interferências preventivas através da detecção precoce e do aconselhamento genético, os objetivos deste trabalho foram:

- Conhecer a prevalência da IRCT na população em tratamento dialítico no município de Campinas e identificar os diagnósticos etiológicos dessa população;

- Estabelecer a prevalência do diagnóstico da doença renal policística autossômica dominante (DRPAD) na população dos pacientes renais crônicos em tratamento dialítico no município de Campinas;

- Identificar os indivíduos portadores de DRPAD em tratamento dialítico no município de Campinas e familiares suscetíveis, para avaliar dados epidemiológicos e detectar o grau atual de conhecimento sobre o modo de transmissão da doença.

No que diz respeito a metodologia, sinteticamente, este estudo foi dividido em três etapas. A primeira parte constou de um estudo descritivo de seccionamento transversal com consulta a dados secundários de uma série de casos, de pacientes renais

\footnotetext{
3 Entende-se aqui por 'tecnologias leves', a forma como se dão as relações entre profissionais de saúde e usuários; a tecnologia de relações, do tipo produção de vínculo, autonomização, acolhimento (acolher aqui como escutar, trocar informações e decidir rumos para dar respostas tecno-assistenciais ao problema apresentado) e responsabilização (a maneira como se responsabiliza por eles). É no estabelecimento de um espaço de escuta entre usuário e profissional que se inícia um processo de trabalho em saúde. Nesta complexa teia de produção de ações em saúde, pode-se verificar que há um conjunto de relações intensas regidas por 'tecnologias leves'que permitem negar ou afirmar direitos, dar maior ou menor capacidade resolutiva às ações, estabelecer maior ou menor responsabilização pelos atos realizados e contribuir para a maior ou menor dependência dos usuários em relação aos serviços prestados. Essas relações são regidas por valores éticos (MERHY,1997).
} 
em tratamento dialítico em Campinas. Foram pesquisados formulários de utilização compulsória pelos serviços de diálise, na Secretaria de Saúde do Estado (DIR 12).

Em um segundo momento, realizamos pesquisa qualitativa com entrevistas semi-estruturadas mediante questionário diretivo, junto a pacientes renais em programa de diálise, com diagnóstico de doença renal policistica, nos próprios locais de diálise. O tratamento destes dados deu-se através da técnica de análise de conteúdo.

A terceira parte constou de pesquisa qualitativa com narrativa livre dos pacientes e representantes das associações de usuários. Nesta etapa para a análise e interpretação dos dados optou-se pela técnica de fragmentação de conteúdo.

\section{APRESENTAÇÃO DOS RESULTADOS}

Campinas contava, à época deste estudo, com quatro unidades de diálise, atendendo a uma demanda não só regional mas também de outros municípios do Estado de São Paulo.

Encontravam-se em procedimentos dialíticos 378 pacientes, sendo 59\% (n=223) do sexo masculino e $41 \%$ ( $n=155)$ do sexo feminino, com idade média de 47,5 anos ( de 1 a 86 anos). A maioria dos usuários viviam maritalmente (66,9\%), seguindo-se 21,2\% de solteiros, $7,3 \%$ viúvos e 4,7\% separados.

O tipo de tratamento mais freqüente foi a hemodiálise $(\mathrm{HD}=245)$, seguida pela diálise peritoneal ambulatorial contínua $(\mathrm{CAPD}=126)$ e a diálise peritoneal intermitente (DPI=7), esta correspondendo a pacientes pediátricos.

Os diagnósticos etiológicos da insuficiência renal crônica dos pacientes em tratamento dialítico verificados em nosso município foram: Glomerulonefrite $(n=103)$, Diabetes Mellitus ( $n=73)$, Hipertensão Arterial $(n=50)$, Indeterminado $(n=44)$, 
Pielonefrite ( $n=25)$, Outros ( $n=24)$, Rim Policístico $(n=23)$, Alport $(n=2)$, Lúpus $(n=4)$.

Os Serviços de diálise dos hospitais universitários de Campinas, particularmente o HC da UNICAMP, têm sido a porta de entrada do sistema de saúde no atendimento ao paciente renal crônico, responsáveis, na maioria dos casos, pela admissão, diagnóstico, tratamento e encaminhamento para outros Serviços da região.

Vale ressaltar que a presença e a participação dos usuários nos Serviços de diálise nos últimos tempos também vêem-se alterando: deixam de ser simplesmente ‘pacientes', passivos, e começam a agir e a organizar-se, entrando em cena de maneira mais ativa através de associações, questionando o Estado, exercendo pressão e controle social sobre a qualidade do tratamento recebido.

A doença renal policística autossômica dominante (ADPKD) é uma das mais importantes e atinge 6,6 \% $(n=23)$ dos pacientes em programa dialítico no município de Campinas. As principais características observadas nos pacientes portadores de doença renal policística entrevistados, foram: predomínio do sexo masculino (57\%), idade superior a 50 anos (74\% ), idade média de 56,5 anos (42-75) e mediana de 56 anos, casados (87\%), residentes em Campinas e região (74\%), 1 o grau incompleto (61,5\%), a maioria beneficiários do INSS (54,4\%), renda até 4 salários mínimos (80\%).

Por estes dados pudemos verificar que a maioria deste grupo de usuários corresponde àquele contingente que apresenta uma superposição de problemas, pertencentes às classes populares, ou seja, de baixo nível de educação e instrução, baixa renda e baixo poder aquisitivo, com uma série de interferências e repercussões nas diversas áreas. 
A partir dos dados levantados nas entrevistas com os usuários portadores da doença renal policística, realizamos mapeamento dos familiares portadores assintomáticos e sintomáticos não diagnosticados ou mal diagnosticados.

Do período de levantamento dos dados até a época da realização das entrevistas com os portadores de doença renal policística verificamos que 4 pacientes haviam sido transferidos para outra região, 6 evoluíram para óbito e 13 permaneciam em tratamento dialítico.

Pela análise dos dados pudemos verificar que dos 13 pacientes entrevistados, 11 possuíam filhos, constituindo um total de 40, com 37 vivos. A maioria destes indivíduos encontrava-se distribuída nas faixas etárias correspondentes à idade produtiva e reprodutiva, variando de 13 a 46 anos.

Da prole analisada, verificamos que 29,7\% ( $\mathrm{n}=11)$ dispunham de diagnóstico de Rim Policístico e os 70,3\% (n=26) restantes ainda não haviam sido investigados, encontrando-se, portanto, desprotegidos e descobertos de ações de caráter preventivo.

Com base nestes registros e considerando-se que a média por paciente foi de 3 filhos, ao extrapolar esses dados para o universo de 23 pacientes referidos e com diagnóstico de Rim Policístico, em diálise no município de Campinas, podemos estimar um número de cerca de 70 filhos que carregam consigo os gens da doença renal policística na comunidade, embora sem diagnóstico e assintomáticos, portanto em risco de desenvolverem a doença e transmiti-la a seus descendentes.

Os dados levantados em investigação junto aos portadores de doença renal policística em tratamento dialítico no município de Campinas, foram agrupados em dois grandes tópicos a partir das questões norteadoras das entrevistas: Conhecimento da doença e Orientações sobre a doença. 


\section{CONHECIMENTO E ORIENTAÇÕES SOBRE A DOENÇA}

Conhecimento da doença refere-se ao modo como o paciente soube que é portador de rim policístico, o período entre o conhecimento da doença e o início da diálise, entre outros.

Orientações sobre a Doença revela as principais informações e (ou) orientações recebidas pelo paciente após o diagnóstico de doença renal policística.

Observamos que 38,5\% $(n=5)$ dos pacientes tomaram conhecimento da doença pela história familiar; 46,1\% $(n=6)$ souberam somente depois do surgimento de sintomas clínicos como hematúria, edema, hipertensão arterial, dores e aumento do volume da massa renal, e 15,4\% (n= 2) após investigação clínica como candidato a doador renal para um familiar.

Pudemos verificar que apesar de tratar-se de doença hereditária e na maioria dos casos já terem “conhecimento” de história anterior através de pessoas da família, os pacientes apresentavam uma atitude de negação da própria doença, ou seja, imaginavam que nunca seriam acometidos pela mesma, sendo de certa forma surpreendidos pelo surgimento dos sintomas.

O tempo do conhecimento do diagnóstico até as manifestações de insuficiência renal crônica e conseqüente início de diálise foi extremamente variável, oscilando desde um tempo inferior a 1 ano até 25 anos, sendo que a maior porcentagem de pacientes (30,7\%) referiu período entre 20 e 25 anos.

Observa-se também que 46,2\% dos pacientes referiram ter tido conhecimento da enfermidade em período inferior a 4 anos, ou seja, apesar da história familiar da doença renal policística, somente conheceram o diagnóstico com o agravamento da sua situação clínica, período em que permaneceram em tratamento conservador. 
A maioria dos pacientes revelou ter recebido orientações quanto à transmissão hereditária da doença (53,9\%), enquanto $15,4 \%$ referiram não ter recebido orientação alguma e ainda outra parcela (30,8\%) apresentou negação ou desconhecimento quanto à gravidade da mesma. Somente $7,7 \%$ dos pacientes tiveram orientação efetiva e positiva sobre a necessidade de se fazer controle clínico da doença.

Embora o termo hereditariedade tenha sido usado pelos pacientes, questiona-se algumas vezes se estes têm a real compreensão e entendimento do que vem a ser uma doença hereditária e do que lhes foi transmitido através do discurso médico.

O usuário, devido a limitações sociais e culturais e por não possuir um equipamento lingüístico mais refinado, capta a mensagem e a informação recebidas e as reinterpreta dentro de seu universo vocabular, sua visão de mundo e seu conceito.

Boltanski (1989) assinala que o termo hereditariedade é freqüentemente utilizado pelas classes sociais mais baixas quando a enfermidade é própria do indivíduo, não se estabelecendo diferença entre ele e a doença, considerada inevitável, fatal, confundindo-se mesmo com predestinação.

Frases como "você não vai morrer desta doença”, "não esquente a cabeça”, "ter vida normal”, “defeito genético”, “tendência familiar” revelam a forma como o médico procura diminuir a ansiedade do paciente ao dar o diagnóstico suavizando a gravidade da doença, deixando de lado a ação preventiva e educativa.

Quanto às outras informações recebidas por ocasião do diagnóstico, verificamos que as de ordem dietética e alimentar, principalmente no que dizem respeito à restrição de sal e redução de ingesta de carne vermelha, foram as mais freqüentes.

Indagados sobre o fato de terem recebido informações sobre a transmissão hereditária da doença, $\mathbf{6 1 , 5 \%}(\mathrm{n}=8)$ responderam afirmativamente. 
Embora a maioria dos pacientes tivesse 'conhecimento' da transmissão hereditária, nenhum fez referência a providências tomadas quanto ao planejamento familiar e uso de anticonceptivo.

Pacientes com família constituída referiam que já tinham todos os filhos na ocasião da manifestação da doença, talvez como justificativa diante do problema. Neste sentido pudemos observar que o único paciente entrevistado, que não teve filhos e optou pela adoção, refere que foi por razões de infertilidade da esposa.

Observou-se também no discurso de um paciente, que foi inicialmente orientado, tratar-se de doença congênita e não hereditária, e pelo seu depoimento, somente ao fazer exames como doador renal para sua mãe é que teve efetivamente conhecimento da questão da hereditariedade.

Questionados sobre a necessidade de mais informações a respeito, todos foram unânimes em reconhecer que a partir do início do tratamento dialítico foram satisfatoriamente conhecendo mais sobre sua doença.

Estas afirmações, entretanto, reiteram que enquanto grupo de risco os pacientes não tiveram acesso à informação e à ação preventiva e somente quando iniciaram o tratamento é que receberam algum tipo de orientação.

Nossos dados, contudo, revelam o relativismo do ‘conhecimento' referido pelo usuário. Esse conhecimento apresenta-se fragmentado, truncado, distorcido, limitado e é, de certa forma, desapercebido pelos profissionais que prestam a assistência.

Observa-se também que, ao avaliarmos o aconselhamento e a orientação, cerca de $50 \%$ dos pacientes receberam 'orientação relativa' e a outra metade nem sequer a recebeu, e, no limite, e paradoxalmente, apenas em tratamento dialítico é que o portador de rim policístico demonstrou ter conhecimento de sua moléstia. Como vemos, o usuário precisa ter seu problema agravado para conhecer a sua doença. 


\section{A INSUFICIÊNCIA RENAL CRÔNICA E A DOENÇA RENAL POLICÍSTICA}

\section{SOB A ÓPTICA DOS PORTADORES DE PATOLOGIAS RENAIS}

Neste estudo, não poderíamos deixar de incluir os depoimentos dos principais alvos de nossa prática profissional: os portadores de patologias renais, que assumem papel importante e se colocam em cena não simplesmente como pacientes, mas como ativos usuários, que trazem uma experiência, de um saber empírico vivido cotidianamente.

O relato dos usuários é produto de elaboração intelectual do entrevistado, um tipo de reflexão, um ponto de vista individual, e reproduz o modo como encaram seus próprios problemas. Os depoimentos dos Presidentes da Associação de Renais Crônicos de Campinas, da Associação Paulista de Renais Crônicos e da Federação das Associações de Pacientes e Transplantados Renais do Brasil não foram tomados como a fala singular de um paciente, mas como o discurso de pessoas que têm a vivência e participam de um processo político que culminou na criação e na implementação destas Entidades que, gradativa e historicamente, vêm assumindo um papel importante na discussão da política de saúde neste setor.

Para a análise destes dados selecionamos alguns tópicos, que nos pareceram significativos, extraídos dos aspectos mais relevantes que buscamos conhecer do discurso do usuário.

\section{Visão do usuário sobre a sua doença.}

O paciente renal crônico passa por diversas situações, no início e no transcorrer de sua doença, que promovem sérios impactos emocionais. A nova relação com a enfermidade e com o conhecimento médico é geradora de ansiedade e tensões. O mundo 
da doença e da medicina é para os membros das classes populares um universo estranho e regido por uma lógica cujas regras ignora (BOLTANSKI, 1989).

A cronicidade e o "stress" do tratamento dialítico freqüentemente têm como conseqüências a depressão e a negação da doença, refletindo a dificuldade de lidar com a nova forma de vida que se apresenta.

Kubler-Ross (1992), ao estudar pacientes portadores de doenças terminais, identifica cinco estágios pelos quais os indivíduos passam para atingir um processo de crescimento psicológico. Esses estágios são: negação, raiva, negociação, depressão e aceitação. Várias dessas situações são constantemente observadas na prática profissional e podem ser constatadas pelo discurso dos próprios usuários.

“As pessoas falam que nem pareço doente. Eu não sou doente, quem é doente é o rim só”

“A doença não atrapalhou nada. No começo eu não aceitava a idéia de ter a doença. Fiquei muito mal, procurei uma psicóloga e tive várias sessões, eu não aceitava o fato de fazer a hemodiálise.”

“... mas quando a doença evoluiu para insuficiência renal e necessitei de diálise, entrei em depressão e até pensei em suicídio.”

“Às vezes entro em depressão, aquela vontade de chorar... O que mais me preocupa são os filhos: será que eles vão passar por isso tudo também , ou daqui há 10 anos vai ser melhor, haverá outras condições?”

“Dizer que ser renal crônico não é problema seria mentira. No meu caso eu tento diminuir a quantidade de problemas e enfrentar como uma coisa mais natural na minha vida”.

A IRCT impõe aos pacientes limites e restrições de várias ordens, sendo que a esfera do social é uma das mais comprometidas, obrigando-os a conviver com várias 
perdas: a atividade profissional, o aspecto econômico, as condições de vida, o "status”, o convívio social.

“Eu parei de trabalhar quando soube que tinha problema de rim. Trabalhava em fábrica, das 5 da manhã até as 5 da tarde, normal, até que comecei a urinar sangue, então comecei a baquear. Entrei no INPS e me aposente”.

“... eu não sou uma pessoa normal, eu tenho consciência disso, sou uma pessoa que tenho os meus limites. Eu trabalho, mas tem dia que não estou disposto, e como eu trabalho por conta não vou trabalhar”.

A fala da presidente da Federação das Associações de Renais e Transplantados do Brasil é muito significativa quando analisa a situação dos pacientes:

"Para a maioria dos pacientes, ser renal crônico é um problema e problema grave, porque o renal é discriminado. Mesmo que ele tenha o tratamento e uma qualidade de vida boa, ele não consegue trabalho, e este é um dos problemas grandes porque se o renal não fosse discriminado ele conseguiria viver muito melhor, estaria produzindo, diminuiria seu problema econômico e satisfação pessoal e estaria sendo útil”.

O discurso acima reflete a forma de como a sociedade moderna está estruturada para lidar com os problemas de saúde da população. A discriminação do paciente pelo mercado de trabalho revela a falta de flexibilidade no mundo do trabalho, que não absorve a mão de obra qualificada como doente, transformando-a em incapaz e excluída.

\section{A questão da afetividade}

O processo da doença interfere sobremaneira no aspecto psicossociofamiliar, refletindo no emocional do paciente. A ocorrência de conflitos afetivos é freqüentemente relatada pelos pacientes, implicando em ruptura de vínculos 
significativos no relacionamento marital, abandono e rejeição, além de um alto grau de disfunções sexuais, tais como a diminuição da libido e a infertilidade, agravando ainda mais sua carência emocional e a insegurança diante do tratamento.

Vários depoimentos fazem referência à importância e à ação benéfica do apoio da família e da equipe de saúde como forma de ajudá-los a superar as dificuldades, contribuindo para a aceitação da doença e a convivência com a mesma.

“Minha família está consciente da doença, mas tem família que não aceita, acha que a pessoa é uma pessoa normal, mas o renal crônico não é uma pessoa normal...”

“Quanto ao sexo não tenho problema, não mudou nada, normal. Sei que tem pacientes que falam que desde que fazem hemodiálise não sentem mais nada.”

“Aqui em casa não me tratam como doente; todos me apóiam, sou muito amigo dos filhos, a família é unida. Os filhos levantam cedo para me levar na clínica, a nora vai buscar...”

O discurso da representante das Associações de Pacientes, analisando as condições emocionais e afetivas do paciente, é revelador das dificuldades e da realidade vivenciada cotidianamente pelos usuários.

“O renal crônico tem problema sério de afetividade, ele vai ficando feio” e começa sendo rejeitado... a maioria dos que são casados são abandonados tanto pela mulher como pelo marido. Quando ele não é bem dialisado, vai para casa com dor porque não tirou toda a água, ele se torna um chato, torna-se um peso para a família, e tem família que aguenta um pouco e tchau. No caso dos velhinhos é terrível, você vê famílias loucas para que morram, é muito complicado”.

A fala da Presidente da FARBRA, na condição de usuária, mostra que é possível conviver com a doença de maneira positiva. 
"Quando eu falo que sou renal, a maioria das pessoas acha que é sofrimento, é claro que não é uma coisa boa, mas para mim não é sofrimento porque eu vivo feliz. Tenho meus filhos, marido, a gente vive a família, participo com tudo, então eu consigo viver sem sofrimento; tenho muitos momentos de alegria, não me impede de eu fazer nada, viajo, só que eu sei de meus limites, tenho o meu objetivo que me faz muito bem e me dá energia de continuar vivendo”.

A doença crônica representa a entrada em um novo modo de vida onde as limitações físicas, sociais e mentais exigem do paciente readaptações constantes devido às mudanças na sua vida profissional, social e econômica. Essas limitações dificultam sua reorganização e a estruturação emocional, pois ocorrem frustrações e fracassos em relação aos planos para o futuro. Decorrem deste fato a necessidade e a importância do apoio da equipe multidisciplinar, onde cada profissional partilha de um espaço do coletivo na divisão social e técnica do trabalho, interferindo na redefinição dos problemas para a sociedade.

\section{Rotina do tratamento dialítico e resultados}

Apesar das dificuldades para a aceitação da doença, no decorrer do tempo o paciente vê-se obrigado a aderir ao tratamento, embora passe por muitos problemas e intercorrências.

O acolhimento da equipe de saúde tem sido relatado como um fator de grande ajuda no processo de aceitação e aderência ao tratamento, uma vez que o usuário portador de doença crônica tem uma vinculação prolongada com o serviço de diálise. A atenção, os cuidados e a empatia presentes na equipe assistencial são fatores que contribuem para a melhoria da qualidade de vida do paciente.

Merhy (1997), ao considerar o processo de trabalho em saúde, salienta a importância da incorporação de 'tecnologias leves’ que podem gerar alterações 
significativas no modo de agir em saúde. Essas tecnologias de e das relações entre profissionais da saúde e usuários, são pautadas na ética do compromisso com a vida e expressas nas dimensões assistenciais do trabalho em saúde e se traduzem pela relação de acolhimento, pela criação de vínculo, e pela responsabilização do usuário.

“Vir para a clínica é um passeio, me sinto muito bem aqui”.

"Eu me sinto disposta, me preparo como se fosse trabalhar, faz parte de minha vida, eu tenho que vir levanto numa boa, não reclamo, pego a condução e faço esta viagem três vezes por semana”.

“... eu não aceitava, passava mal na máquina. As enfermeiras ajudam muito, a equipe toda, os próprios pacientes, eles dão muito exemplo...”

“... a equipe é maravilhosa, é fora de série, são prestativos, têm um respeito muito grande pelo paciente”.

A viabilização de uma abordagem interdisciplinar deve ser vista como uma forma de proporcionar a atenção integral ao usuário, que se encontra fragilizado diante de sua necessidade de saúde.

Entretanto, no discurso de outro usuário pode-se também considerar:

“... o que me decepcionou foi a relação médico-paciente. É uma relação meio falha, é claro que eles têm muitas pessoas para cuidar, mas eu fiquei muito tempo no hospital, desesperado, sem uma orientação. Eu não tive o direito de saber como era a minha situação, eu estava inseguro sem saber o que ia acontecer...”

Vale ressaltar que a comunicação médico-paciente é extremamente importante. Boltansky (1989) enfatiza que o mutismo do médico só reforça a ansiedade e desconfiança dos pacientes das classes populares face à doença, sendo mesmo reprovado por estes por não usar de franqueza e omitir a informação. 
A doença renal e a hemodiálise são fontes constantes de "stress", angústia e insegurança para o paciente e exigem sensibilidade e tato nas relações entre usuário e a equipe. O acolhimento e o vínculo formado com a equipe de saúde têm um efeito terapêutico fortalecedor que repercute positivamente na vida do usuário.

\section{Participação dos usuários no processo da oferta dos serviços}

Ao analisarmos a IRCT, observamos que os portadores de doenças renais têm uma série de problemas, pois a maioria representa parte do contingente da população de um nível educacional inferior, de pessoas com baixa renda e baixo poder aquisitivo, o que implica em menor grau de participação, pelas próprias condições de exclusão em que se encontram.

Observa-se também que a maioria dos pacientes renais apresenta uma falta de interesse e reduzida participação em atividades sociais e de lazer, refletindo na dificuldade de assumirem o próprio tratamento crônico, devido aos vários problemas que enfrentam em decorrência dos limites da própria doença.

A fala dos pacientes reflete sua pouco expressiva participação em movimentos sociais enquanto forma de pressão e controle social, como é o caso das Associações de Pacientes Renais.

“Fica difícil participar da associação por morar em outra cidade, teria que vir mais para Campinas, mas se for para participar indiretamente, eu sempre contribuo com as promoções, eu posso ajudar sem ter que ir às reuniões, deixa para quem tem mais tempo de ir atrás das coisas”.

“Toda associação tem um lado falho, eu fui convidado, mas é difícil, você não tem respaldo político, não consegue, eu gostaria de doar um tempo meu mas sou ocupado. Tem que ter associação para tentar fazer alguma coisa pelo pessoal, eu acho que justifica mas ela ainda está fraquinha”. 
A visão que a maioria dos pacientes tem da Associação é assistencialista, devendo canalizar seus esforços para atender às necessidades dos usuários mais carentes, uma vez que nem todos têm acesso aos medicamentos necessários e que não se encontram disponíveis na rede pública. São, portanto reivindicações incipientes e têm muito para avançar:

“... é importante porque eles conseguem o remédio pra gente, sem ter que comprar...”

"Vários pacientes podem comprar a medicação, têm um poder econômico melhor, mas outros nem o salário têm, ou ganham salário mínimo, não têm condição nem de comer”.

Poucos pacientes reconhecem que a Associação de usuários deve desempenhar um papel político, organizado, reivindicatório de controle social para garantir a qualidade e a melhoria do atendimento à saúde. É o que podemos identificar no discurso da Presidente da Federação:

“O renal não tem visão do poder dele enquanto cidadão, não só ele mas todo o brasileiro. Há muitos que acham que são uns coitadinhos, que têm que ser atendidos, mas não fazem nada para mudar, ficam violentos, agressivos, cobram muito , mas não saem do nível da cobrança. Há outros ainda que fazem da doença um meio de vida. Isso é a miséria do renal, porque é uma vida tão sacrificada, não tem emprego, e quando ele pode levar vantagem ele vai tirar proveito, não dá para condenar, é a vida de miséria, muitas vezes ele tenta vender o próprio remédio que a Secretaria da Saúde dá. Agora, tem o sacana que compra com preço abaixo do mercado”.

“A própria doença limita muito a adesão do paciente à Associação, ele fica preso à máquina, não tem nenhum estímulo. O paciente tem muito medo da 
participação e há muita repressão por parte dos médicos que não estimulam a participação do paciente”.

As Associações têm objetivado ajudar o paciente no entendimento de seu próprio processo e no enfrentamento da doença, colocando-se como aliados fundamentais na luta pela conquista de direitos, de garantias no acesso e acompanhamento especializado, conscientizando o usuário das suas condições de cidadão.

\section{Acesso a informações e prevenção}

Pudemos constatar que a grande maioria dos pacientes não tem conhecimento suficiente das origens, causas e conseqüências da sua doença. Este desconhecimento não se restringe somente à doença, mas também ao funcionamento dos órgãos e à anatomia humana. Observa-se também especificamente no caso da doença renal policística, com implicações na questão da reprodução dos indivíduos em risco, que a orientação e informação recebidas na maioria das vezes não esclareceram suficientemente sobre a gravidade e o impacto nas futuras gerações.

A despeito da necessidade de informações, o paciente muitas vezes sente-se incapaz de perguntar ao médico e a outros profissionais da equipe de saúde o que deseja saber, devido a limitações culturais, que muitas vezes o impedem de entender o que dizem, sendo suas interpretações baseadas em seu repertório e referencial cultural. Outras vezes, devido ao distanciamento na relação médico-paciente, provocado pela própria relação assimétrica, refletida muitas vezes na pouca disponibilidade, capacidade e sensibilidade para dar informações.

O grau de escolaridade e a classe social do paciente também contribuem significativamente para tal situação. As relações sociais são também relações 
ideológicas e, embora as classes sociais diferentes sirvam-se de uma mesma língua, a palavra também se torna arena onde se desenvolve a luta de classe (MINAYO, 1996).

Boltanski (1989) analisa a comunicação entre médico e doente, onde se observa uma barreira linguística, pois a utilização, pelo médico, de um vocabulário especializado aumenta a separação entre a língua das pessoas cultas e a das classes populares. Assim, as explicações dadas pelo médico ao doente variam efetivamente em função da classe social do paciente, detendo-se em detalhes àqueles que julga evoluídos para compreenderem o que vai ser explicado.

Sendo a maioria dos pacientes provenientes do contingente econômico e cultural mais baixo, sua capacidade de abstração dificulta uma maior compreensão do processo saúde-doença e, conseqüentemente, as explicações recebidas. Este fato pode ser confirmado pelos depoimentos que se seguem:

“Os filhos sabem que têm rim policístico, mas por enquanto a gente procura não conversar muito sobre isso, pois traz preocupação muito antes do tempo...”

“...eu falo para os filhos que eu no lugar deles não teria filhos e eles falam que não, que a medicina muda muito e quem sabe se até lá as coisas melhoram”.

“Eu e meu marido quando conversamos, ele diz que se soubesse que eu teria esse problema de rim, a gente não teria tido os filhos”.

“Tenho preocupação com os filhos e converso bastante com eles, que pensam em fazer vasectomia, adotar uma criança, eles sabem bem o fator genético que há 50\% de chance dos filhos terem a doença...”

Observa-se também o caráter contraditório do discurso sobre a doença, quando o paciente alega desconhecimento, embora tenha vários casos na família:

“Tive vários familiares com a doença, tios já falecidos, uma irmã, um irmão que também faz hemodiálise aqui, uma sobrinha que está cheia de problemas, ela não 
aceita de jeito nenhum... e meu filho com 19 anos, já foi feito investigação, ele tem a doença ... Eu não teria os filhos se soubesse e se tivesse sido orientado. Já tinha meus filhos quando soube porque a doença só desenvolveu quando eu tinha 40 anos. Se fosse hoje eu não teria os filhos não”.

A maior parte dos pacientes revelam uma atitude de passividade ao encarar a doença como uma fatalidade, algo imutável, inevitável nas famílias portadoras de doença renal policística. Torna-se, portanto, necessário fazer uma revisão nos programas de educação em saúde, a fim de se proporcionar maior impacto e mudança de atitudes na população.

No depoimento da presidente da FARBRA pudemos verificar que há pouca preocupação quanto à prevenção das várias doenças renais:

“Eu não vejo as equipes muito preocupadas com o paciente. Existe uma falta de sensibilidade, não há preocupação com a prevenção, de melhorar a qualidade de vida, entra no todo essa falta de preocupação com a prevenção neste caso do rim policístico”.

“Eu acho que há algumas doenças que têm que ser prevenidas. Para que fazer que as futuras gerações continuem levando a doença se há um meio de acabar? Tem que ser duro e firme. A genética diz que se tiverem filhos vai continuar transmitindo a doença, então vamos parar esse processo. Não ter filho não é nenhum problema no mundo, adota, tem tanta criança precisando de uma família, adota. Que amor é esse que você vai querer ter um filho que pode vir doente?”.

Estes depoimentos, extraídos do contato direto com os usuários, confirmam a deficiência da informação e conhecimento da doença e a necessidade e importância de se conhecer a epidemiologia da doença e implementar ações protetoras e preventivas para que se evitem maiores custos sociais e sofrimento humano. 
O desafio para as equipes multidisciplinares é estimular a participação dos usuários em Associações para que no contexto das políticas públicas de saúde, exerçam seu papel de pressão e controle, e através da troca de saberes e experiências sobre o processo saúde-doença, contribuam para o aumento da autonomia dos pacientes.

\begin{abstract}
ABSTRAT
The lack of epidemiological data of the end-stage renal disease (ESRD) in Campinas lead us to investigate the Autosomal Dominant Polycystic Kidney Disease (ADPKD), the most common hereditary disorder, that can be prevented through early detection and genetic counseling. The analysis of the data enables us to know the prevalence of ambulatorial ESRD and identify the differents ethiological diagnostics of the population in renal replacement therapy in Campinas. These data allow us identify the patients in dialysis in the city of Campinas, evaluate the epidemiological and demographic features and identify the degree of knowledge about the inheritability transmission of ADPKD. In addition, we observed an insufficient iteration between the health professional team and the patients, and with relatives. These observations suggest a prevention program in the community throughout 'soft technologies' with pedagogic alternatives to the low educated people aimed to improving knowledge of the disease and independence of the patients.
\end{abstract}

KEYWORDS: End stage renal disease; Autosomic dominant kidney disease; Public health; Genetic counseling; Prevention program.

\title{
REFERÊNCIAS BIBLIOGRÁFICAS:
}

AGODOA, L.Y.; EGGERS, P.W. Renal replacement therapy in the United States: data from the United States Renal Data System. American Journal Kidney Disease, Philadelphia, v. 25, n. 1, p. 119-133, 1995. 
AJZEN, H.; SESSO, R. C. Tratamento dialítico do paciente renal crônico. Revista da Associação Medica Brasileira, São Paulo, v. 41, n. 1, p. 1-2, 1995.

ARAÚJO, J. D. Polarização epidemiológica no Brasil. Informe Epidemiológico do SUS, MS/CENEPI/FNS, Brasília, ano 1, n. 2, p. 5-16, 1992.

BOLTANSKI, L. As classes sociais e o corpo. 3. ed. Rio de Janeiro: Graal, 1989. $191 \mathrm{p}$.

BROYER, M.; GAGNADOUX, M. F. Polycystic kidney disease in children. In: CAMERON, S. et al. Oxford Textbook of Clinical Nephrology. Oxford: Oxford University Press, 1992. v. 3, p. 2163-2185.

FALEIROS, V. P. Serviço Social: questões presentes para o futuro. Serviço Social e Sociedade. São Paulo: Cortez, 1996. n. 50, p. 9-39.

FRANZ, K. A.; REUBI, F. C. Rate of functional deterioration in polycystic kidney disease. Kidney International, Cambridge, v. 23, p. 526-529, 1983.

KUBLER-ROSS, E. Sobre a morte e o morrer. 5 ed. São Paulo: Martins Fontes, 1992.

LAURENTI, R. Transição demográfica e epidemiológica. In: CONGRESSO BRASILEIRO DE EPIDEMIOLOGIA, 1., 1990, Campinas. Anais... Rio de Janeiro: ABRASCO, 1991. p.143-165.

MARCONDES, M. Nefrologia. In: MARCONDES, M.; SUSTOVICH, D. R.; RAMOS, O. L. Clínica médica: propedêutica e fisiopatologia. Rio de Janeiro: Guanabara Koogan, 1976. p. 353-434.

MERHY, E. E. Em busca do tempo perdido: micropolítica do trabalho vivo em saúde. In: MERHY, E. E.; ONOCKO, R. (Org). Agir em saúde: um desafio para o público. São Paulo: HUCITEC, 1997. p. 71-112.

MINAYO, M. C. S. O desafio do conhecimento: pesquisa qualitativa em saúde. 4. ed. São Paulo: HUCITEC, 1996. p.269. 
NETTO, J. P.; FALCÃO, M. C. Cotidiano: conhecimento e crítica. 2 ed. São Paulo: Cortez, 1989. 93 p.

PIRSON, Y.; GRUNFELD, J. P. Autosomal-Dominant Polycystic Kidney Disease. In: CAMERON, S. et al. Oxford textbook of clinical nephrology. Oxford: Oxford University Press, 1992, v.3, p. 2171-2188.

RAMALHO, A. S. As hemoglobinopatias hereditárias: um problema de Saúde Pública no Brasil. Ribeirão Preto: Sociedade Brasileira de Genética, 1986.

RAMALHO, A. S.; BERTUZZO, C. S.; SILVA, R. B. P. Aconselhamento Genético.

Medical Máster Atualização Médica, São Paulo, v. 2, p. 209-213, 1994.

CONGRESSO DE NEFROLOGIA DA SOCIEDADE BRASILEIRA DE

NEFROLOGIA, 27.; REGISTRO BRASILEIRO DE DIÁLISE E TRANSPLANTE

RENAL, 5., 1994, Fortaleza, Anais... 52 p.

REICHENHEIM, M. E.; WERNECK, G. L.- Adoecer e morrer no Brasil dos anos 80: perspectivas de novas abordagens. In: GUIMARÃES, R.; TAVARES, R. Saúde e Sociedade no Brasil, anos 80. Rio de Janeiro: Relume Dumara, 1994. p.113-129. SEDMAN, A. et al. Autosomal dominant polycystic kidney disease in childhood: a longitudinal study. Kidney International, Cambridge, v. 31, p. 1000-1005, 1987. VERAS, R. P.; ALVES, M. I. A população idosa no Brasil: considerações acerca do uso de indicadores de saúde. In: MINAYO, M. C. S. (Org.). Os muitos Brasis: saúde e população na década de 80. São Paulo: HUCITEC, 1995. p. 320-337.

WATSON, M. L. Complications of polycentric kidney disease. Kidney International, Cambridge, v. 51, p. 353-365, 1997. 
